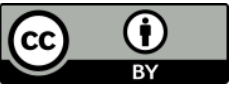

\title{
Arquitetura multimodal da geoinformação no processo de comunicação cartográfica
}

Carita da Silva Sampaio

Geógrafa. Mestre em geoprocessamento para o planejamento territorial. Doutoranda em ciência da informação pela Universidade de Brasília

Cláudio Gottschalg Duque

\begin{abstract}
Graduação em Licenciamento em Letras habilitação em Alemão pela Faculdade de Letras da Universidade Federal de Minas Gerais (1994). Mestrado em Programa de Pós-Graduação em Estudos Lingüísticos pela Faculdade de Letras da Universidade Federal de Minas Gerais (1998). Doutorado-sanduíche em Angewandte Sprachwissenschaft und Computerlinguist Justus-Liebig-Universität Giessen (2004). Doutorado em Programa de Pós-Graduação em Ciência da Informação pela Escola de Ciência da Informação (2005). Professor Adjunto do Depto. de Ciência da Informação e Documentação da Universidade de Brasília (CID-UnB)
\end{abstract}

http://dx.doi.org/10.1590/1981-5344/2870

A busca pela relevância é uma característica básica da cognição humana. Considerando que o intervalo entre a construção e o uso dos mapas é um processo comunicacional, profissionais das geociências podem explorar a condição da busca pela relevância para aperfeiçoar o atendimento das necessidades de diversos usuários de mapas. Este artigo fundamenta-se em debater em que medida a Teoria da Relevância e a abordagem da Multimodalidade podem contribuir para a ampliação do uso dos mapas, partindo do princípio do menor esforço e do discurso multimodal no processo comunicacional. O objetivo foi ampliar as formas de representação dos fenômenos geográficos modelados para o ambiente computacional para que os mapas atendam necessidades relevantes e, portanto, sejam mais úteis. Para alcançar este objetivo, o artigo apresenta um 
experimento utilizando elementos da geoinformação, da Teoria da Relevância e da Multimodalidade. Nas considerações finais, apresenta possibilidades de estudos futuros.

Palavras-chave: Arquitetura da Informação, Multimodalidade, Geoinformação.

\section{Multimodal Architecture in Geoinformation Cartographic Communication Process}

The search for relevance is a basic feature of human cognition. Whereas the interval between the construction and the use of maps is a communication process, geosciences professionals can explore the relevance of the search condition to better serve the needs of many users maps. This article is based on debate to what extent the relevance theory and approach of Multimodality may contribute to the increased use of maps, based on the principle of least effort and multimodal speech in the communication process. The objective is to discuss the validity of the identification of a set of modes involved in the production (experts) and use (user) so that the geoinformation maps meet relevant requirements, and hence are more useful. To accomplish this, the article presents an experiment using elements of geoinformation, the relevance theory and Multimodality. In the final considerations, it presents further study possibilities.

Keywords: Information Architecture. Multimodality. Geoinformation.

Recebido em 06.07.2016 Aceito em 17.05.2018

\section{Introdução}

Os mapas são documentos e, portanto, contêm informação. Eles têm como atributo personalizado a localização geográfica, sendo então, geoinformação. Partindo do pressuposto que mapas são representações de proposições (ou ideias) que, do ponto de vista comunicacional, sempre terão ruídos, pode-se abordar estes mapas a partir da Teoria da Relevância (SPERBER; WILSON, 1986a), bem como da Multimodalidade (KRESS, 2009; 2010). Ambas, teoria e abordagem metodológica podem 
ser instrumentos de ampliação da capacidade cognitiva de compreensão do processo de interpretação de mapas e seu conteúdo semiótico.

A comunicação humana é realizada por meio de modos, variados, simultâneos, resultados da interação social. Assim, a comunicação cartográfica pode ser obtida e descrita a partir de variados instrumentos de comunicação, como em um discurso multimodal. Com a disponibilização dos sistemas orbitais de posicionamento terrestre (GPS ${ }^{1}$ ) e os avanços das tecnologias embarcadas em dispositivos móveis, quase todas as aplicações tecnológicas desenvolvidas atualmente contêm geoinformação como atributo definitivo.

Este recurso informacional, tradicionalmente utilizado somente por especialistas, atualmente é ferramenta de trabalho, negócio e lazer de um número nunca imaginado de usuários. A partir dessa constatação observase que o universo de usuários de mapas ampliou-se significativamente, demandando estudos não só na área de engenharia cartográfica tradicional, mas na pertinência e relevância dos mapas para antigos e novos usuários. Isso implica dizer que a produção da geoinformação deve ser cada vez mais relevante para um determinado domínio do conhecimento ou grupos específicos de usuários.

A relevância, para Sperber e Wilson (1986a), é característica básica da cognição humana. No processo comunicacional existe o princípio do menor esforço. Este princípio consiste em que o comunicante deve ser ostensivo o suficiente em apresentar as suas ideias e cabe ao seu receptor uma atitude proativa, para que a informação seja recebida, inferida e transformada em conhecimento. Essa ostensividade está relacionada com a relevância da proposta de comunicação para ambas as partes.

Partindo do pressuposto que mapas são representações semióticas de proposições (ou ideias) a respeito de fenômenos geográficos e que, do ponto de vista comunicacional, sempre terão ruídos, a proposta aqui apresentada é assumir esse ruído analisando-o sob o aspecto da multimodalidade. A abordagem da multimodalidade serve como instrumento de avaliação e subsídio para a identificação dos modos atualmente disponíveis que permitam a ampliação e melhoria do processo de comunicação cartográfica.

Neste contexto, o objetivo desse artigo foi realizar um experimento inicial que associa a Geoinformação à Teoria da Relevância e à abordagem da Multimodalidade dentro da Ciência da Informação, para identificação de variados discursos multimodais no processo de comunicação cartográfica, com a finalidade de ampliar as formas de representação dos fenômenos geográficos modelados para o ambiente computacional.

\section{Geoinformação e teoria da relevância}

Ampliar a capacidade semântica de uma informação passa pela capacidade cognitiva de fazer escolhas relevantes necessárias à

Global Position System pertencente aos EUA. Além do sistema GPS, existe a constelação GLONASS da Rússia e a iniciativa do sistema GALILEU da União Europeia. A China também tem um projeto de sistema de posicionamento terrestre em construção. 
interpretação de seu significado. Os objetos disponíveis na superfície terrestre e que podem ser representados a partir de signos (PRADO et al., 2000), quando mapeados, são resultado de escolhas feitas pelo seu interpretante com relação ao seu significado e à sua relevância (SPERBER; WILSON, 1986b). Neste campo, duas teorias remetem a uma terceira que dão sentido ao pensamento aqui exposto: a teoria cognitiva da atenção e a teoria do processamento da informação que dão corpo para a teoria da relevância.

A teoria cognitiva da atenção e a teoria do processamento da informação reforçam que a atenção é seletiva, possui gargalos de informação e varia de indivíduo para indivíduo. Estes processos estão ligados tanto ao processamento consciente quanto ao processamento automático da informação. Tais teorias são comprovadas em estudos de hipermídia adaptativa provenientes da ciência da computação (BRUSILOVSKY, 1996). Estes estudos são baseados na melhoria dos processos de navegação e interatividade em ambientes web, onde o foco são os interesses dos usuários daquela informação. Um ambiente de hipermídia adaptativa permite que o conteúdo de uma página interativa se adapte ao universo de conhecimento do usuário, sugerindo hiperlinks relevantes.

O processo de produção da geoinformação é uma das etapas da comunicação cartográfica. Os objetos dispostos na superfície terrestre possuem significados (provenientes da interação social e da cultura) e podem ser representados por meio de signos. E estes signos devem ser relevantes para usuários cada vez mais diversificados, sendo esse o desafio da produção de geoinformação na atualidade. Dessa forma, a TR é subsídio teórico importante para fundamentar as necessidades de adaptação da geoinformação às necessidades reais de velhos e novos usuários de mapas.

\section{Geoinformação e multimodalidade}

A linguagem não é o único veículo capaz de produzir a comunicação entre os pares e suas culturas. Estudos de semiótica com Peirce (1972) se destacam, revelando que a comunicação se dá, também, por meio de imagens e iconografia, inclusive com a comunicação cartográfica (SAMPAIO; DUQUE, 2013). Em meio a este contexto surge a multimodalidade, uma abordagem científica originada na linguística e na pedagogia que permitiu o uso de novos instrumentos de investigação científica no processo de comunicação.

Gunther Kress (2009) questiona e explica: o que é modo? Basicamente, o processo comunicacional é muito mais complexo do que inicialmente se imagina. Mesmo estando sozinho, o comunicante está se relacionando com um mecanismo de comunicação físico ou virtual produzido por outro comunicante. Este processo de construção, codificação e interpretação da informação é objeto de estudo da multimodalidade. 
A multimodalidade é definida por Carey Jewitt (2009) como uma abordagem científica baseada em variadas formas de comunicação (linguagem, postura, gestos, imagens, olhar, entre outros), que correlaciona os conceitos de modo, recursos semióticos, metafunções, capacidade modal e relacionamento intersemiótico, com a finalidade de ampliar a dimensão de análise do processo comunicacional a partir da variedade de recursos e formas de realiza-lo.

Para Kress (2010), cada modo empregado em um discurso multimodal, tem função específica, com potencial distinto para a construção do significado. Assim, a multimodalidade é considerada como o estado normal da comunicação humana. No entanto, apesar da multimodalidade poder identificar os modos utilizados, não pode diferenciar o estilo de cada modo, pois não dispõe de recursos para esse fim. Há que se ter uma teoria que lide com o significado em todas suas instâncias, em todas as situações sociais e em todos os sítios culturais. Essa teoria é a semiótica social (HALLIDAY, 1978).

Desde a década de 90, investigações detalhadas têm sido empreendidas com o intuito de descrever recursos semióticos, funções e sistemas de múltiplos modos, organizando seus princípios e apontando para suas referências culturais. A "gramática visual", elaborada por Kress e Van Leeuwen (2006), vem contribuindo significativamente para mapear os recursos semióticos presentes na comunicação visual. Nesse domínio, é possível incluir pesquisas relacionadas aos modos semióticos das cores (KRESS; VAN LEEUWEN, 2002), da tipografia (VAN LEEUWEN, 2006), dos gestos e movimentos (MARTINEC, 2000), e do olhar (LANCASTER, 2001; BEZEMER, 2008). Nesta última década, pode-se destacar as pesquisas realizadas também no âmbito da voz e da música (MACHIN, 2007; STEVENS, 2009).

Na Ciência da Informação, Aldo Barreto (ZINS, 2007) define que o objeto de estudo da CI é a organização, produção, controle e o uso da informação por meio de qualquer canal. Para Brandão e Duque (2011) a informação só se completa se for utilizada. Completando este pensamento, no ambiente digital, onde a interatividade é estimulada, o tempo existente entre os que produzem e os que consomem informação é bem menor. Reunindo estas abordagens, a análise aqui proposta ressalta que essa interatividade passa por um discurso multimodal.

E se a geoinformação, insumo dos mapas, também é resultado de instâncias sociais localizadas, sua representação ocorre por um sistema semiótico de múltiplos modos, tanto no processo de produção como no de uso da geoinformação, modos que podem ser investigados a partir da abordagem da multimodalidade.

\section{Experimento multimodal da geoinformação categoria vegetação}

Com base no arcabouço teórico apresentado, este artigo propôs-se realizar um estudo de caso inicial para verificar o uso da multimodalidade e dos requisitos de ostensividade da Teoria da Relevância para identificar 
diferentes modos de distinção e representação de entidades do modelo de dados geoespaciais da Especificação Técnica da Estrutura de Dados Geoespaciais Vetoriais (ET-EDGV ${ }^{2}$ ) do mapeamento brasileiro, mais precisamente da categoria temática "vegetação".

Assim, o método escolhido para o tipo de pesquisa qualitativa foi o experimento (CRESWELL, 2007). O experimento utilizou uma variedade de discursos multimodais para investigar, com especialistas da área de geoinformação, como a utilização de diferentes modos apresentam resultados diferentes para a representação dos fenômenos geográficos modelados para o ambiente computacional na EDGV ${ }^{3}$.

$\mathrm{Na}$ especificação EDGV 3.0, as categorias de informação são divididas em três grupos:

1) O primeiro apresenta as categorias cujas classes de objetos compõem o Mapeamento Topográfico em Pequenas Escalas ${ }^{4}$ (MapTopoPE);

2) O segundo grupo apresenta as categorias cujas classes de objetos são normalmente adquiridas no Mapeamento Topográfico em Grandes Escalas ${ }^{5}$ (MapTopoGE); e

3) No último grupo, a Cartografia Temática de Defesa da Força Terrestre (CTD), cujas categorias de informações são relacionadas às atividades de defesa e segurança dos Grandes Eventos, ou aquelas que são úteis para tal (Defesa Civil, Redes de Serviços Públicos, entre outras).

$\mathrm{Na}$ modelagem conceitual das categorias de informações do MapTopoPE, as classes de objetos são agrupadas seguindo a premissa básica de observar o aspecto funcional comum. Para as categoriais do MapTopoGE, esta premissa nem sempre pode ser observada. $O$ MapTopoGE privilegia a aquisição de dados em escala grande, geralmente planimétrica e com maior nível de detalhamento, apresentando elevada precisão geométrica. Normalmente é utilizada para representar as feições de cidades e regiões metropolitanas, nas quais a densidade de edificações e arruamentos é considerável.

Para o recorte de dados, foi escolhido o segundo grupo, o de categoria de informações do Mapeamento Topográfico em Grandes Escalas (MapTopoGE) (Quadro 1). Ele é composto das seguintes classes de objetos:

\footnotetext{
${ }^{2}$ A ET-EDGV é uma das especificações técnicas previstas no âmbito da Infraestrutura Nacional de Dados Espaciais (INDE). A INDE é coordenada pela Comissão Nacional de Cartografia (CONCAR) que tem responsabilidades distribuídas entre o IBGE e a Diretoria de Serviço Geográfico do Exército Brasileiro (DSG/EB). A ET-EDGV é responsabilidade da DSG/EB. Disponível em: <http://www.geoportal.eb.mil.br/index.php/inde2?id=139>. Acesso em: 1 jul. 2016.

${ }^{3}$ A versão utilizada para o experimento foi a 3.0 .

${ }^{4}$ De $1: 250.000$ a $1: 25.000$.

${ }^{5}$ Acima de 1:10.000.
} 


\section{Quadro 1 - Categorias de informações do Mapeamento Topográfico em Grandes Escalas}

\begin{tabular}{|c|c|c|}
\hline Seção do Anexo B & Categoria & Definição \\
\hline Seção 1 & Área Verde (VER) & $\begin{array}{l}\text { Agrupa as feições que representam } \\
\text { os espaços urbanos públicos com } \\
\text { predomínio de vegetação. }\end{array}$ \\
\hline Seção 2 & $\begin{array}{l}\text { Mapeamento Topográfico em } \\
\text { Grandes Escalas - Classes Base }\end{array}$ & $\begin{array}{l}\text { Agrupa as feições que representam } \\
\text { as classes consideradas básicas e de } \\
\text { uso comum no Mapeamento } \\
\text { Topográfico em Grandes Escalas, } \\
\text { com exceção das feições } \\
\text { altimétricas. }\end{array}$ \\
\hline Seção 3 & Cultura e Lazer (LAZ) & $\begin{array}{l}\text { Agrupa as feições que representam } \\
\text { as estruturas físicas dos sistemas } \\
\text { associados à cultura, lazer e esporte. }\end{array}$ \\
\hline Seção 4 & Desenvolvimento Social (DS) & $\begin{array}{l}\text { Agrupa as feições que representam } \\
\text { as estruturas físicas dos sistemas } \\
\text { associados às atividades de } \\
\text { atendimento de públicos e prestação } \\
\text { de serviços das políticas de } \\
\text { desenvolvimento social, tais como } \\
\text { assistência social, segurança } \\
\text { alimentar, transferência de renda e } \\
\text { inclusão produtiva. }\end{array}$ \\
\hline Seção 5 & Edificações (EDF) & $\begin{array}{l}\text { Agrupa as feições que representam } \\
\text { os diferentes tipos de edificações no } \\
\text { contexto urbano e rural. }\end{array}$ \\
\hline Seção 6 & Equipamento Urbano (EUB) & $\begin{array}{l}\text { Agrupa as feições de Segurança } \\
\text { Pública e as das categorias SAU, } \\
\text { EDU e DS, caracterizando assim os } \\
\text { bens públicos ou privados, de } \\
\text { utilidade pública, destinados à } \\
\text { prestação de serviços necessários ao } \\
\text { funcionamento da cidade, } \\
\text { implantados mediante autorização do } \\
\text { poder público, em espaços públicos e } \\
\text { privado. }\end{array}$ \\
\hline Seção 7 & $\begin{array}{l}\text { Estrutura de Mobilidade Urbana } \\
\text { (EMU) }\end{array}$ & $\begin{array}{l}\text { Agrupa as feições que representam } \\
\text { as estruturas físicas relacionadas aos } \\
\text { deslocamentos de pessoas e bens } \\
\text { dentro de um espaço urbano. }\end{array}$ \\
\hline Seção 8 & Patrimônio Público (PPB) & $\begin{array}{l}\text { Agrupa as feições que representam o } \\
\text { conjunto de bens materiais, } \\
\text { históricos ou culturais do poder } \\
\text { público federal, estadual ou } \\
\text { municipal. }\end{array}$ \\
\hline
\end{tabular}

Fonte: Especificação Técnica da Estruturação de Dados Geoespaciais Vetoriais (ET-EDGV $3.0,2016)$.

O experimento realizado para este artigo selecionou a seção 1 da referida categoria de informações, que diz respeito às áreas verdes 
urbanas. Pela definição da ET-EDGV 3.0 (2016), estas áreas agrupam feições que representam os espaços urbanos públicos com predomínio de vegetação. Em grandes escalas, é possível confundir parques públicos com unidades de conservação que demonstram fragmentos de vegetação natural referente ao bioma específico.

As três áreas verdes foram escolhidas dentro do território do Distrito Federal. O insumo para produção das imagens de "áreas verdes" no Distrito Federal foi o mosaico de ortofotos com resolução de $0,24 \mathrm{~cm}$ no Distrito Federal fornecido pela Companhia de Planejamento do Distrito Federal (Codeplan/DF) por meio de geoserviço ${ }^{6}$. Do mosaico de imagens, foram retirados três recortes de lugares onde apareciam áreas verdes, sem que o usuário especialista soubesse sua localização real (Figura 1).

O critério para essa escolha foi a variação dos tipos de áreas verdes possivelmente encontradas no ambiente urbano e que se distinguem em: (i) parques urbanos (arborizados com plantas frutíferas voltados somente para o lazer), (ii) canteiros (normalmente áreas da gestão urbanística da cidade voltadas a passeios de pedestres e separação entre vias e rodovias) e (iii) áreas de proteção permanente (APPs, são áreas de conservação ${ }^{7}$ de vegetação natural ao longo dos cursos d'água, inclusive em ambiente urbano).

Figura 1 - Áreas verdes selecionadas para aplicação do experimento de representação multimodal da geoinformação

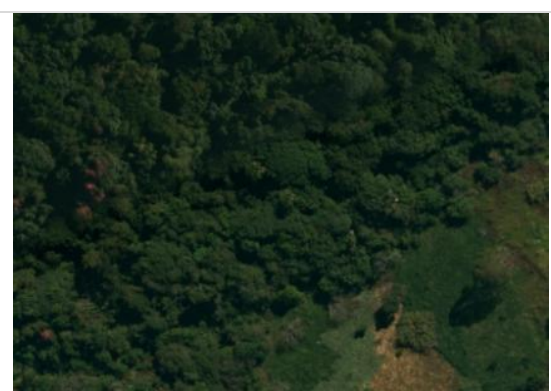

Área verde 1 - Parque Urbano Águas Claras, Brasília/DF.

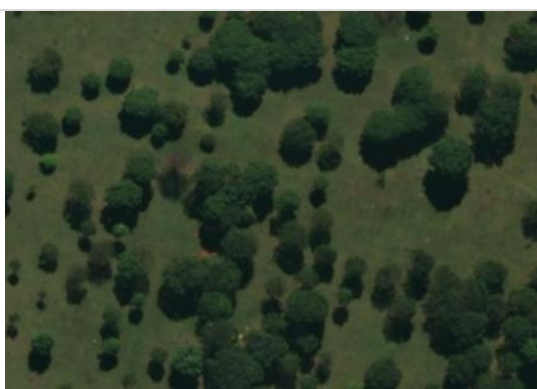

Área verde 2 - Canteiro central do eixo monumental ao lado do Estádio Nacional, Brasília/DF.

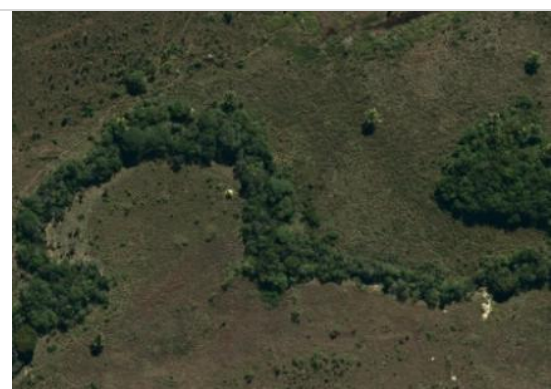

Área verde 3 - Área de Proteção Permanente (APP) do Córrego Gama ao lado do aeroporto, Brasília/DF.

Fonte: Elaboração dos autores com base nas ortofotos do Distrito Federal disponível em: <www.ortofoto.mapa.codeplan.df.gov.br>. Acesso em: 1 jul. 2016.

A natureza e função dessas áreas verdes são totalmente distintas, mas sua representação em mapas cadastrais torna-se tarefa difícil pelo alto grau de detalhes naquelas escalas cartográficas. Exatamente por isso a categoria de informação "área verde" do MapTopoGE da EDGV 3.0 generaliza essa tipologia e não procura distingui-la. Essa diferenciação passa, então, a ser função da fase de representação.

O processo tradicional de representação das categorias de informações geoespaciais modeladas para ambientes computacionais

\footnotetext{
${ }^{6}$ Disponível em: <www.ortofoto.mapa.codeplan.df.gov.br>. Acesso em: 1 jul. 2016.

As APPs são reguladas pelo Código Florestal, revisto em 2012 pela Lei no 12.651, de 25 de maio de 2012 (BRASIL, 2012).
} 
ainda não atende aos requisitos de implementação automatizada a partir de um método de interpretação desses modelos. Este experimento é o início de uma possibilidade de construção de um método para uma arquitetura multimodal da representação da geoinformação.

O objetivo do experimento consistiu em expor especialistas da área de geoinformação a três modos de entrar em contato com a classe de objeto "áreas verdes" da ET-EDGV 3.0 (2016) presente na categoria de informações do Mapeamento Topográfico em Grandes Escalas para descrever, também de modos diferentes, os tipos de representação possíveis.

Para elaboração do experimento foram realizados os seguintes passos metodológicos (Figura 2):

Figura 2 - Passos metodológicos para realização do experimento de representação multimodal da geoinformação

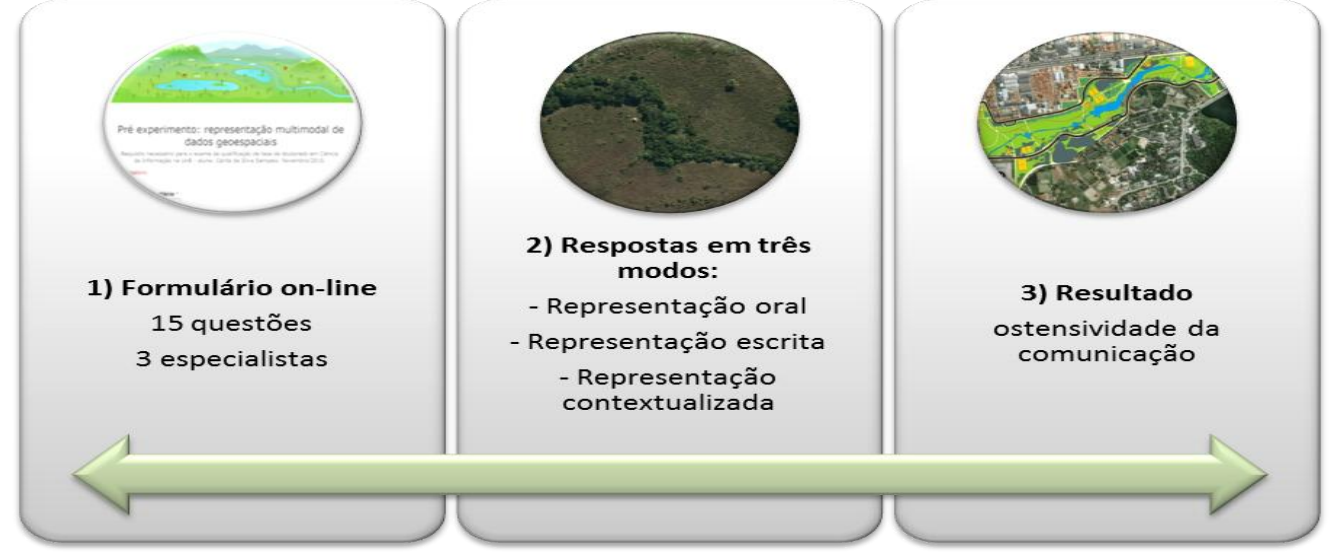

Fonte: Elaboração dos autores (2016).

Primeiro, a elaboração de um formulário eletrônico contendo 15 questões e dividido em três seções, para cada uma das três áreas verdes, com as seguintes abordagens: (i) a representação oral da área verde analisada; (ii) a representação escrita da área verde analisada e (iii) a representação escrita contextualizada da área verde analisada.

$\mathrm{Na}$ primeira seção o especialista gravou um áudio e enviou um arquivo pelo próprio formulário. Na segunda seção ele inseriu o texto agregando informações ou não do áudio. Na última seção, o entrevistado passou a relatar a representação tendo em mãos uma ferramenta de mapas web colaborativo ${ }^{8}$ para que ele pudesse se localizar e, a partir disso, identificar e descrever a representação da área verde em questão.

Segundo, o envio do formulário a três especialistas da área de engenharia cartográfica via e-mail. Por fim, a análise dos resultados interpretando o grau de ostensividade dos entrevistados ao apontarem o tipo de representação para cada uma das três áreas verdes selecionadas.

\section{Resultados}

\footnotetext{
${ }^{8}$ Openstreetmap. Disponível em: <http://www.openstreetmap.org>. Acesso em: 1 jul. 2016.
} 
A primeira verificação do experimento foi analisar se os especialistas saberiam reconhecer as áreas verdes apenas pela imagem em grande escala, sem localização e contexto. O percentual de erro foi de $100 \%$ para a primeira área verde (parque urbano), 66,66\% para a segunda área verde (canteiro) e $100 \%$ de acerto para a terceira área verde (APP) (Figura 3).

Figura 3 - respostas dos entrevistados quanto ao tipo de área verde no experimento

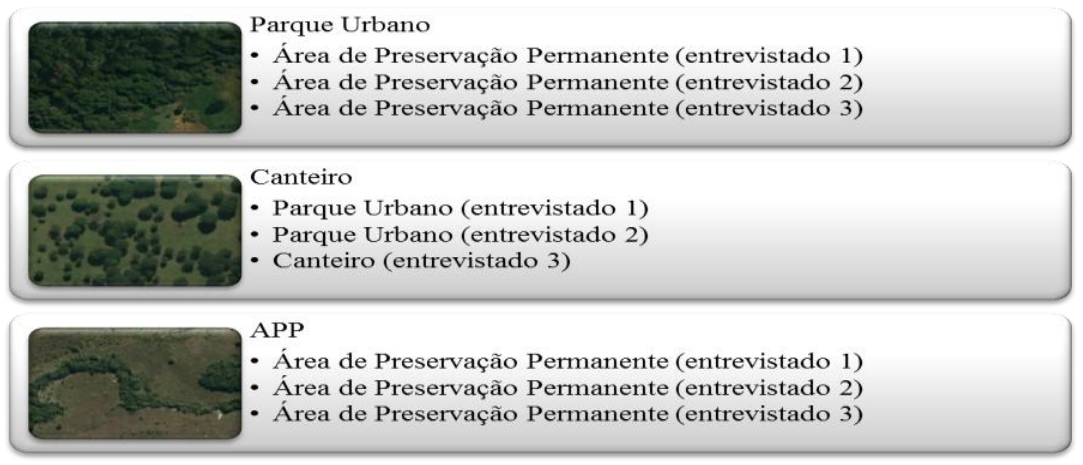

Fonte: Elaboração dos autores (2016).

Este primeiro resultado demonstra que o especialista fica limitado a identificar as áreas verdes utilizando apenas um tipo de modo. Isso o leva, já no início do processo de representação, a um erro que redundará em uma informação com ruído, confusa e até mesmo errada para o usuário do mapa. Por mais que a modelagem de dados geoespaciais esteja adequada para as estruturas de bancos de dados e as relações entre suas entidades, de acordo com seus conceitos, se a representação não estiver mais próxima do mundo real, o usuário final não terá uma informação útil.

A segunda verificação foi com relação ao tipo de representação para cada uma das áreas verdes. Neste momento do experimento, o especialista respondeu, de três modos diferentes, como iria criar a representação semiótica da categoria áreas verdes da EDGV 3.0 distribuída por tipos.

Utilizando inicialmente somente um modo, o oral, os especialistas descreveram as representações cada um de uma forma diferente. Agregando o segundo modo, a escrita, os especialistas aparentemente agregaram valor à informação e dois deles já informaram o mesmo tipo de representação. Mas é com o terceiro modo, a escrita contextualizada com o mapa colaborativo, que os três especialistas definem a representação com mais uniformidade, onde os três descrevem a mesma forma de representação (Figura 4).

Figura 4: respostas dos entrevistados quanto às formas de representação das áreas verdes no experimento 


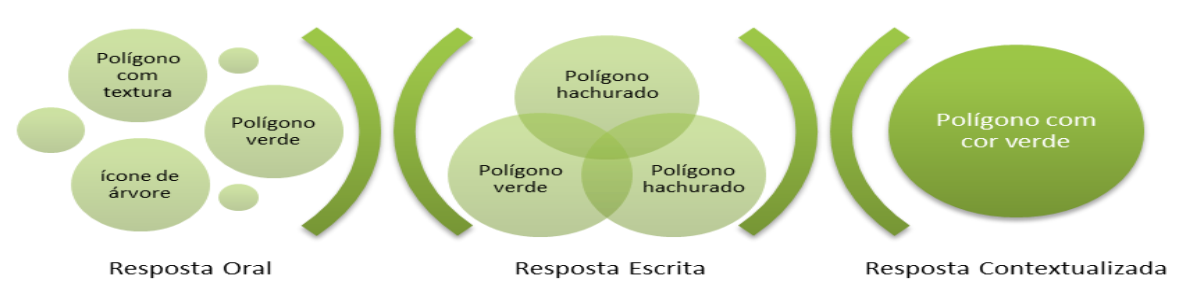

Fonte: Elaboração dos autores (2016).

É possível verificar que, quanto maior a quantidade de modos para identificação do significado de cada uma das classes de objetos do modelo de dados geoespaciais, maior será a capacidade do especialista em escolher representação mais adequada para cada um dos fenômenos geográficos.

\section{Considerações finais e trabalhos futuros}

A existência de teorias, métodos e instrumentos para a investigação científica é o que permite o contínuo avanço da ciência. Este artigo mostrou por meio da teoria da relevância e da abordagem da multimodalidade que a geoinformação retratada em mapas é um processo de comunicação cartográfica com sujeitos, objetos e resultados que podem ser avaliados à luz do arcabouço teórico-metodológico citado.

A partir desta afirmação, é possível investigar como é possível melhorar o processo de comunicação cartográfica com a finalidade de atender as necessidades dos usuários, considerando a relevância e os aspectos multimodais envolvidos no processo de comunicação e na representação dos objetos geoespaciais modelados para ambientes computacionais. $O$ experimento apresentado neste artigo demonstrou ser útil para aplicação das teorias e abordagens envolvidas, abrindo vasto campo de investigação, como a pesquisa do tipo exploratória sugere.

Diante do cenário de ampliação do universo de usuários, a produção e o uso dos mapas deverá passar, cada vez mais, por observações com relação ao sistema social no qual foi produzido e ao qual se destinará. Para isso, experimentos baseados no arcabouço teórico proposto com cartografia digital e sistemas de informação geográfica são exemplos de estudos futuros.

Também como estudos futuros, duas investigações já são possíveis de serem realizadas partindo dos resultados desse primeiro experimento. A primeira é que os tipos de representação das áreas verdes relatadas pelos especialistas podem ser submetidos a usuários não especialistas para comparar a usabilidade dessa informação entre tipos de usuários diferentes, com diferentes necessidades.

Como o grau de diferenciação de representação entre uma classe e outra foi baixo, de acordo com as respostas dos especialistas (hachuras, texturas, polígonos), outra proposta seria investigar sugestões de representações mais discretas entre as classes de objetos a partir do processo de descrição de cada uma delas por meio de vários modos de 
observação, como os três utilizados no pré-experimento, correlacionando um ao outro.

\section{Referências}

BEZEMER, J. Silent communication in the multilingual classroom. In: CONGRESSO MUNDIAL DE LINGUÍSTICA APLICADA-AILA, 2008, Esen. Anais... Esen: AILA, 2008. p. 25-29.

BRANDÃO, C. O.; DUQUE, C. G. Comunicação científica contemporânea e de vanguarda. In: DUQUE, C. G. (Org.). Ciência da Informação estudos e práticas. Brasília: Centro Editorial, 2011. p. 9-33.

BRASIL. Lei no 12.651 , de 25 de maio de 2012. Dispõe sobre a proteção da vegetação nativa; altera as Leis nos 6.938, de 31 de agosto de 1981, 9.393, de 19 de dezembro de 1996, e 11.428, de 22 de dezembro de 2006; revoga as Leis nos 4.771, de 15 de setembro de 1965, e 7.754, de 14 de abril de 1989, e a Medida Provisória no 2.166-67, de 24 de agosto de 2001; e dá outras providências. Diário Oficial da União, 28 maio 2012. Disponível em: <http://www.planalto.gov.br/ccivil_03/_ato20112014/2012/lei/112651.htm >. Acesso em: 1 jul. 2016.

BRUSILOVSKY, P. Methods and techniques of adaptive hypermedia. User Modeling and User-Adapted Interaction, v. 6, n. 2-3, p. 87-129, 1996.

CRESWELL, J. W. Projeto de pesquisa: métodos qualitativo, quantitativo e misto. 2. ed. Porto Alegre: Artmed, 2007.

ESPECIFICAÇÃO técnica da estruturação de dados geoespaciais vetoriais 3.0 (ET-EDGV 3.0). 2. ed. Brasília, DF, 2016. Parte 1. Disponível em: <http://www.geoportal.eb.mil.br/index.php/inde2?id=139>. Acesso em: 1 jul. 2016.

HALLIDAY, M. A. K. Language as social semiotic. London: Edward Arnold, 1978.

JEWITT, C. Introduction of multimodality. In: HANDBOOK of Multimodal Discourse Analysis. London \& New York: Routledge, p. 14-27, 2009.

KRESS, G.; VAN LEEUWEN. Reading images: the grammar of visual design. 2. ed. London; New York: Routledge, 2006.

KRESS, G.; VAN LEEUWEN. Colour as a semiotic mode: notes for a grammar of colour. Sage publications, London, v. 1, p. 343-368, 2002.

KRESS, G. What is mode? In: HANDBOOK of Multimodal Discourse Analysis. London; New York: Routledge, 2009. p. 54-67.

KRESS, G. Multimodality: a social semiotic approach to contemporary communication. New York: Routledge, 2010.

LANCASTER, L. Staring at the page: the functions of gaze in a young child's interpretation of symbolic form. Journal of Early Childhood Literacy, v. 1, n. 2, p. 131-152, 2001. 
MACHIN, D. Introduction to multimodal analysis. London: Hodder Arnold, 2007.

MARTINEC, R. Types of processes in action. Semiótica, v. 130, n. 3/4, p. 243-268, 2000.

PEIRCE, C. S. Semiótica e filosofia: textos selecionados. São Paulo: Cultrix, 1972.

PRADO, A. B.; BARANAUSKAS, M. C. C.; MEDEIROS, C. M. B. In: BRAZILIAN SYMPOSIUM ON GEOINFORMATICS, 2., Rio de Janeiro, 2000. Anais... Cartografia e sistemas de informação geográfica como sistemas semióticos: uma análise comparativa. [s.n.]: PUC-Rio, 2000.

SAMPAIO, C. S.; DUQUE, C. G. Comunicação cartográfica: semântica em ferramentas de mapeamento colaborativo na web. DataGramaZero Revista de Informação, v. 14, n. 3, ago. 2013. Disponível em: <http://www.dgz.org.br/ago13/Art_04.htm>. Acesso em: 29 jul. 2015.

SPERBER, D.; WILSON, D. Relevance: communication and cognition. Cambridge, MA: Blackwell, Oxford and Harvard University Press, 1986a.

SPERBER, D.; WILSON, D. On defining relevance. In: GRANDY, R.; WARNER, R. (Ed.). Philosophical grounds of rationality: intentions, categories. Oxford: Oxford University Press, 1986b. p. 143-158.

STEVENS, M. Music and image in concert. Sydney: Music and Media, 2009.

VAN LEEUWEN, T. Towards a semiotics of typography. Information Design Journal, v. 14, n. 2, 2006.

ZINS, C. Conceptions of Information Science. Journal of the American Society for Information Science and Technology, v. 58, n. 3, p. 335-350, 2007. Disponível em: <http://www.success.co.il/is/zins_conceptsof_is.pdf >. Acesso em: 29 jul. 2015. 